\title{
The Present Position of Sociology*
}

$\mathrm{N}$ considering the achievement of sociology, the
principal problems can be set out under four
heads.

Social Morphology, including (1) the quantity and quality of the population in so far as this affects social relations and the character of social groups, and (2) social structure, that is, the classification and analysis of the principal types of social groups and social institutions.

On the qualitative side, early studies were dominated by the hypothesis of racial differences in mental character without realization of its difficulties. Their successors are represented by the eugenists and the numerous race theories of civilization, although it is probable that culture is independent of race, and that changes in social structure do not depend on changes in inherited structure. It would appear from studies of the distribution of intelligence in the various social groups that there is no conclusive evidence of genetic difference between the social classes. A good deal of work has been done on the question whether the existing difference in fertility among various social groups is likely to affect the inborn constitution of the stock. Since the differences between the groups are not genetic, the dangers of deterioration on this score are not great. There is no reason to believe that the lower social grades are being drained of ability through the operation of the social ladder. Studies of social mobility lead to the conclusion that conditions making for greater mobility would also make for greater equality in the distribution of wealth, and differential fertility, so far as it is conditioned by varying standards of life, would tend to disappear. A social system which is based on justice and equity would, on the hypothesis of genetic differences, be the most eugenic of agencies.

The subject of social stratification has recently attracted attention widely. It is now possible to give estimates of the proportions of the social classes in the different European countries. The proportion of middle class in Germany is about 34 per cent of the occupied population, in France about 40 per cent, and in England about 25 per cent, though these figures are not comparable, owing among other things to the differences in the number of peasant proprietors in these countries; while in England since 1881 the ratio of increases of the middle class is placed by Prof. Bowley at 100:195, as against an estimate of the ratio of increa ses of the working classes of $100: 168$-an interesting commentary on the theory sometimes urged that the middle class is in process of elimination. An interesting result of recent studies in social mobility is the relatively caste-like character of the higher ranges in the world of business. In Germany, in the main, big industrialists, big business leaders, and big landowners are self-recruited; while in America, too, big business is increasingly self-recruited, and tends to become caste-like, the self-made man now being rare. It is generally recognized that one of the major sources of instability in modern democracy is Substance of a paper by Prof. M. Ginsberg to Section F
(Economics) at the Cambridge meeting of the British Association, read on August $19,1938$. to be found in group conflicts represented in the multiplication of political parties and in the drastic measures taken in authoritarian countries to abolish all parties save one. The position of the middle classes is of special importance in this connexion, as is the whole problem of occupational restratification, which has evidently been going on in Europe since the Great War.

Social Control. The sociology of social control is at bottom part of the sociology of social structure, since clearly a great deal of the structure of society consists in the norms regulating and controlling behaviour in law, morals, religion, conventions and fashion. To the sociologist, the most important types of problem are the differentiating characters of the norms, the conditions under which they arise, and their influence on social conditions and on one another, while important psychological problems are connected with all.

There are many who think that the chief diffi. culties that confront the modern world in the effort to bring about some form of unity among classes and peoples are due to different valuations that are found among them. Others hold, on the contrary, that with regard to the fundamental ends of life there is general agreement, and that the clash of contradictory opinions relates rather to the means which have to be adopted in order to attain these ends. It is surely of the greatest importance to ascertain wherein the difference really arises, and this is not possible without a careful study of the actual beliefs and behaviour of individuals and groups, and a careful discrimination of the factual from the valuational components of moral judgements.

Social Process. In evolutionary sociology, among points which appear important are: First, that sociologists have not yet succeeded in establishing any general laws of social evolution, though this is not to say that significant trends do not occur. There has been, for example, an enormous process of unification, including increase in the size of political aggregates and in intercommunication and interdependence, political and economic, and possibly, despite cultural diversity, an underlying assimilation, or convergence, in science, art, religion, and culture. Secondly, there is an increase in the command of the conditions of life, intensified by increasing knowledge of Nature, including mind and society. Thirdly, various experiments have been made in reconciling order with freedom, and there has emerged in the consciousness of man the sense of the unity of mankind and the need for reconciling the requirements of order and liberty on a world-scale. Fourthly, if development has occurred in the history of humanity, it has certainly not been automatic or rectilinear, and its continuance in a given direction is not secured. Fifthly, if development has occurred, it has been uneven, and advance in one direction has often constituted a hindrance to advance in others.

Increase in the scale of organization has often been achieved at the cost of freedom, and collective efficiency may result in stultifying and thwarting the deepest needs of individuals. The growth of 
knowledge and the command over the conditions of life has also been extremely uneven. Our powers over inorganic Nature are much greater than our powers over life, mind and society; and since the former may be used for purposes of destruction, there is danger that before mankind has acquired sufficient knowledge of the causes of social change, and sufficient moral wisdom to use it aright, the whole structure may be wrecked, and the work of organizing mankind may have to be begun all over again. Scale of organization is of especial importance at the present time.

Self-development even on the part of large communities is becoming more difficult and precarious. This infinitely complicates the problem of reconciling order with freedom. Both logical and historieal analysis suggest that efficient control over the forces of external Nature and of the inner nature of man must rest upon an organization on a world scale, and must rely on methods which can call forth the spontaneous responses of all its members in the service of ends they can recognize as common.
Social Pathology. This brings out the complexity of social causation and the importance of bringing together the results of different modes of investigating and interpreting social phenomena. Taking one example only, the study of cause of crime has to be approached by way of broad social and economic studies, such as (1) correlating various types of crime with social and economic variables, such as price-rate of commodities, density of population, rural and urban conditions of life, etc.; (2) genetic studies; and (3) individual case-study, to which belong therapeutic methods of psychopathology. So little has been done to view the facts in relation one to another, that at different times undue prominence has been given to one or other factor in the causation of crime. To the sociologist taking a broad view it is clear that no invariant relation can be established between any single factor and crime, while these factors in themselves are complex and by no means independent. There are signs that the sociological method of approach is beginning to influence the study of crime both in Great Britain and in the United States.

\section{Agricultural Research in India*}

$\mathrm{T}$ HE Imperial Council of Agricultural Research was set up as a result of the Royal Commission on Agriculture in India in 1926. One of the conditions laid down was that the Council's activities should be periodically reviewed by some disinterested expert, and in 1936 Sir John Russell was invited to make an extensive tour of the provinces with this end in view, in so far as plant industry was concerned.

Sir John's report has now been published. The volume is divided into two parts, the first of which describes the type of agriculture, the crops and the factors which make for improvement in their yield, the special difficulties confronting Indian agriculture and the machinery for dealing with them. In the second part of the report, the various research schemes fostered by the Council and in progress throughout the country are described in detail.

Agriculture in India is not merely an industry but also the mode of life of a large part of the population, and in consequence the scope of the Council's activi. ties is of a far-reaching nature. Village improvement is in fact an essential preliminary to any fundamental advance in agriculture. The gulf that separates the experiment stations and the few large-scale farmers from the peasants, who cultivate the largest proportion of the land, needs to be bridged, and this is rendered peculiarly difficult to effect owing to the absence of the educated middle class farmers, who form such an important section of the farming community of the West.

A vast amount of pioneering work has been successfully accomplished by the Council since its formation, and the necessary extension now lies in the co-ordination of theory with practice, that is, work in the field rather than in the laboratory, increased productiveness being always the central problem. The great increase in the area under cash * Report on the Work of the Imperial Council of Agricultural
Research in Applying Science to Crop Production in India. (Delhi : Manager of Publications, 1937.) crops such as cotton, sugar cane and tea, compared with that under food crops, is one of the most remarkable features of modern Indian agriculture, and although much progress has been made both in their production and utilization, particularly in the case of sugar cane, greater co-operation with the buyers is desirable. Advances in this direction have already been made in the case of cotton and tea, as each crop has its own research station, which is in touch with the appropriate buyers. Similarly, work on food crops needs to be carried out in association with nutrition experts, and inquiries made into the possibilities of extending dairy husbandry and fruit and vegetable growing, if diet is to be raised to a more satisfactory level.

In view of the supreme importance of water supply, the establishment of a separate research institute for the study of irrigation and water relationships between soil and crops is deemed desirable. The proper unification of dry farming schemes is, of course, equally important. Questions concerning soil erosion and alkali trouble might well be dealt with by a soil conservation committee, which could also usefully collect and collate results of manurial trials and soil analyses. Similarly, matters relating to crop planning schemes and insect and fungus pests might be in the hands of a crop production committee, which would provide a convenient central body for co-ordination. Special problems such as locust control, on the other hand, need their own organization, and in spite of the fact that invasions only occur sporadically, a permanent service seems eminently desirable, so that immediate action may be taken when the need arises. The Imperial Agricultural Research Institute recently opened at New Delhi will, no doubt, play a specially important part in the co-ordination of the Council's schemes, and its programme be largely determined by the most pressing problems of the moment. A number of questions to which it could usefully give attention are suggested in the report. 